\title{
Pengembangan Strategi pada Pengelolaan Kedai Kebun Forum Yogyakarta
}

\author{
Faisal Akbar \\ Program Pascasarjana Institut Seni Indonesia Yogyakarta, \\ Jalan Suryodiningratan No. 8, Yogyakarta-55143 \\ E-mail: alienartland502@gmail.com
}

\begin{abstract}
ABSTRAK
Penelitian tentang Pengembangan Pengelolaan Kedai Kebun Forum, Yogyakarta, DIY bertujuan untuk mengidentifikasi strategi, menganalisis faktor internal dan eksternal, serta memformulasikan pengembangan strategi yang sesuai untuk KKF dalam mencapai tujuan yang telah ditetapkan. Metode penelitian yang digunakan dalam penelitian ini adalah kualitatif deskriptif dengan tahap awal yakni menentukan lingkup penelitian (objek dan subjek penelitian), melakukan teknik pengumpulan data (data primer dan data sekunder), menentukan variabel faktor internal (kekuatan dan kelemahan), dan faktor eksternal (peluang dan ancaman), kemudian melakukan analisis data dengan menggunakan teknik analisis SWOT. Penelitian ini menghasilkan: (1) Berdasarkan matriks IE, pengelolaan KKF berada pada posisi V yakni Hold and Maintain (pertahankan dan pelihara). Strategi umum yang dipakai adalah penetrasi pasar dan pengembangan produk; (2) Berdasarkan kuadran analisis SWOT, pengelolaan KKF menunjukkan posisinya berada pada kuadran I yaitu Expansion mendukung strategi ofensif; (3) Berdasarkan hasil matriks SWOT, strategi yang diterapkan yakni penggunaan setiap kekuatan untuk menghadapi setiap ancaman. Kondisi ini mendukung strategi ofensif guna menciptakan peluang, posisi tersebut mengarah pada strategi ST (Strengths - Threats).
\end{abstract}

Kata kunci: pengembangan strategi, ruang seni alternatif, analisis SWOT, formulasi strategi

\section{Strategy Development in the Management of \\ “Kedai Kebun Forum” Yogyakarta \\ ABSTRACT}

The research on the Management Development of Kedai Kebun Forum, Yogyakarta aims to identify strategies, analyze internal and external factors, and formulate the development of appropriate strategies for $K K F$ in achieving the goals that have been set. The research method used is descriptive qualitative with four stages. First, determine the scope of research (object and subject of research). Second, collect data (primary data and secondary data). Third, determine the variables of internal factors (strengths and weaknesses) and external factors (opportunities and threats). Lastly, analyze the data using the SWOT analysis technique. This research resulted: (1) Based on the IE matrix, the management of KKF is in position V, namely, Hold and Maintain. The general strategy used is market penetration and product development; (2) Based on the quadrant of the SWOT analysis, the management of KKF shows its position is in quadrant I, namely Expansion supporting the offensive strategy; (3) Based on the results of the SWOT matrix, the strategy applied is the use of every force to deal with every threat. This condition supports the offensive strategy to create opportunities, the position leads to the ST (Strengths - Threats) strategy.

Keywords: strategy development, alternative art space, SWOT analysis, strategy formulation 


\section{PENDAHULUAN}

Hadirnya ruang seni sebagai ruang publik di Yogyakarta, tentu tidak lepas dari upaya dan konsisten dalam menunjukkan eksistensinya melalui berbagai praktik seni kepada masyarakat. Yogyakarta menjadi pusat kelahiran, pertumbuhan, dan perkembangan khususnya seni rupa (seni tradisional, seni modern, seni pascamodern) di Indonesia. Wacana mengenai ruang seni mencuat pada tahun 90-an dengan tumbuhnya berbagai "ruang seni non-galeri" yang sering juga disebut sebagai ruang seni alternatif. Kemunculan ruang seni alternatif ini mengakomodasi para seniman dan karya-karya eksperimental yang tidak diterima oleh galeri komersial. Galeri alternatif terbagi atas dua karakteristik dari aspek konsep operasional, yakni otonom (hanya ruang pamer) dan ada yang menyatu dengan fungsi lain (Fulkova, 2011).

Salah satu ruang seni alternatif yang menyatu dengan fungsi (aktivitas) lain di Yogyakarta adalah Kedai Kebun Forum (KKF), yang didirikan pada tahun 1997. Dikelola secara independen oleh Yustina Neni (Direktur Kedai Kebun Forum), Agung Kurniawan (Direktur Artistik Kedai Kebun Forum), dan Uniph Kahfi (Koordinator Program Kedai Kebun Forum). KKF terdiri dari galeri, ruang pertunjukan, bookstore, dan restoran. Selama ini seluruh aktivitas di KKF dibiayai oleh restorannya. Lokasi KKF berada di dekat pusat keramaian, yakni di Jalan Tirtodipuran No. 3, Mantrijeron, Kota Yogyakarta, Daerah Istimewa Yogyakarta. Faktor lokasi turut menguatkan aksesibilitas, membuka peluang lebih besar bagi masyarakat awam untuk datang secara langsung melihat atau mengikuti kegiatan seni yang diadakan oleh KKF.

Banyaknya ruang seni alternatif yang gagal mempertahankan eksistensinya di dunia seni rupa, salah satunya dikarenakan tidak adanya rencana atau strategi jangka panjang. Perlu adanya pengelolaan dalam menyepakati arahan, sasaran serta program jangka panjang untuk menghadapi pertumbuhan internal, dan perubahan lingkungan eksternal (Dani, 2019). Ruang seni menjadi kata kerja bukan kata benda, karena ada orang yang mengelolanya. Kata kelola berkaitan dengan dengan manajemen. Dalam konteks ruang seni, manajemen tidak hanya secara finansialnya saja, melainkan juga terkait dengan manajemen sosial, serta manajemen gagasan.

Upaya dalam menjalankan bisnis maupun aktivitasnya, KKF perlu menerapkan pola manajemen yang efektif, efisien, dan kontekstual dengan kebutuhan dan ketersediaan sumber daya. Serta menerapkan tiga hal penting, yakni membangun citra, meluaskan jaringan, dan menguatkan program. Tiga hal tersebut mampu saling berintegrasi satu sama lain. Dengan demikian, program kegiatan ruang seni nantinya bisa lebih kaya, meluas, dan mematangkan citra sebagai ruang seni (Indarto \& Santoso, 2015). Diperlukan perencanaan strategi yang tepat dengan menggunakan metode SWOT (Strengths, Weaknesses, Opportunities, dan Threats) sebagai landasan dasar dalam membuat keputusan untuk menghadapi segala 
kendala dan tantangan dengan memanfaatkan potensial yang dimiliki (internal) maupun potensi yang bersifat eksternal. Pada penelitian ini berfokus pada manajemen strategi yang sesuai untuk KKF agar dapat mengoptimalkan serta mampu mempertahankan eksistensinya di dunia seni rupa.

\section{Landasan Teori}

\section{A. Manajemen Strategi}

Manajemen strategi dibutuhkan dalam merumuskan, mengimplementasi, serta mengevaluasi berbagai keputusan (pemasaran, produksi, keuangan, sumber daya manusia, dan sistem informasi) yang menghasilkan formulasi dan implementasi demi mencapai tujuan organisasi (David \& David, 2017). Manajemen strategi dapat didefinisikan sebagai proses pengambilan keputusan manajemen dalam mengembangkan (perencanaan dan pengorganisasian) serta menjaga stabilitas (pengarahan dan pengontrolan), berdasarkan keputusan dari manajer puncak dengan menggunakan sumber daya organisasi (internal) dan lingkungan (eksternal) yang berubah-ubah. Berdasarkan fungsi-fungsi tersebut diharapkan menjadi sebuah rujukan dasar bagi manajer puncak dalam menjalankan aktivitas pengelolaan dalam upaya mencapai tujuan yang diinginkan mampu terealisasi secara efisien dan efektif.

\section{B. Analisis SWOT}

SWOT adalah singkatan dari strengths (kekuatan), weaknesses (kelemahan), opportunities (peluang), dan threats (ancaman), dibutuhkan pada proses pengambilan keputusan strategi terkait pengembangan misi, tujuan, strategi, dan kebijakan organisasi dengan memaksimalkan kekuatan dan peluang serta mampu meminimalkan kelemahan dan peluang (Rangkuti, 2018). Analisis SWOT menjadi alat dalam perencanaan strategi yang digunakan untuk menganalisis kesesuaian antara sumber daya internal dengan situasi eksternal organisasi saat ini. Perlu dilihat faktor internal dan eksternal untuk mengetahui faktor pendorong dan penghambat terkait upaya pengelolaan organisasi dalam analisis SWOT, yaitu:

\section{Faktor Internal}

Terkait dengan kondisi yang dekat dan berada di dalam organisasi (pemasaran, keuangan, operasional, sumber daya manusia, sistem informasi manajemen, dan budaya perusahaan) yang memengaruhi terbentuknya pembuatan keputusan terkait kekuatan (strengths) dan kelemahan (weaknesses).

\section{Faktor Eksternal}

Terdiri atas kondisi-kondisi di luar organisasi (lingkungan industri dan lingkungan bisnis makro, ekonomi, politik, teknologi, dan sosial budaya) yang memengaruhi pembuatan keputusan terkait peluang (opportunities) dan ancaman (threats). 


\section{METODE PENELITIAN}

\section{A. Jenis Penelitian}

Penelitian ini menggunakan pendekatan kualitatif deskriptif dengan memfokuskan terhadap satu objek tertentu agar diperoleh deskripsi atau gambaran yang jelas secara intensif, baik secara menyeluruh maupun mengenai aspek-aspek tertentu dari kondisi dan proses pengelolaan yang saat ini sedang dilakukan oleh $\mathrm{KKF}$.

\section{B. Objek dan Lokasi Penelitian}

Objek penelitian ini adalah pengelolaan di Kedai Kebun Forum sedangkan lokasi penelitian terletak di Jalan Tirtodipuran No.3, Mantrijeron, Kota Yogyakarta, Daerah Istimewa Yogyakarta, 55143.

\section{Subjek Penelitian}

Subjek dari penelitian ini adalah stakeholder (pengelola inti) yang menaungi dan mengelola seluruh kegiatan yang dilakukan oleh Kedai Kebun Forum terdiri dari tiga orang, yakni Yustina Neni sebagai Direktur Kedai Kebun Forum, Chairol Imam sebagai seniman muda (praktisi), dan Vitasari sebagai pengunjung KKF.

\section{Teknik Pengumpulan Data}

Menggunakan data primer yang diperoleh secara langsung di lapangan melalui wawancara, observasi, dan kuesioner serta data sekunder melalui studi pustaka. Metode wawancara dilakukan langsung dengan mengadakan tanya jawab kepada subjek yang diteliti. Metode observasi dilakukan dengan melihat langsung ke lapangan terhadap objek yang diteliti sebagai upaya mengumpulkan data dan informasi dari sumber data primer. Metode kuesioner dilakukan untuk mendapatkan penilaian terkait faktor kekuatan, kelemahan, peluang, dan ancaman pada pengelolaan KKF, diisi oleh responden yang dinilai ahli dan memiliki informasi mendalam terkait dengan objek penelitian. Studi pustaka, dilakukan menggunakan sebagian atau seluruh data yang telah ada dari penelitian sebelumnya, dokumen-dokumen dari KKF, baik dalam bentuk web, buku, booklet, dan rekaman audio.

\section{E. Metode Analisis Data}

Metode analisis data pada penelitian ini menggunakan dua metode analisis yaitu menggunakan analisis kualitatif secara deskriptif dan analisis SWOT. Metode analisis kualitatif deskriptif digunakan untuk memaparkan data-data yang ditemukan di lapangan kemudian data akan dianalisis secara kualitatif, baik yang berasal dokumentasi, rekaman arsip, wawancara, serta observasi langsung. Datadata tersebut selanjutnya akan dianalisis menggunakan analisis SWOT yang merupakan singkatan dari strengths (kekuatan), weaknesses (kelemahan), opportunities (peluang), dan threats (ancaman). Analisis SWOT didasarkan pada kesesuaian antara sumber daya internal dengan situasi eksternal perusahaan. 


\section{HASIL DAN PEMBAHASAN}

\section{A. Sejarah Kedai Kebun Forum}

Kedai Kebun Forum adalah komunitas kecil yang didirikan untuk usaha belajar dan pengkajian, dalam rangka membangun kepekaan terhadap setiap gejala perubahan sosial, melalui kesenian. Digagas dan dikelola oleh pasangan seniman Yustina Neni dan Agung Kurniawan sejak September 1997 sebagai sebuah restoran dan galeri alternatif. KKF memiliki ruang yang dapat digunakan sebagai tempat untuk pameran seni rupa, pertunjukan teater, musik, tari, workshop, pembacaan puisi atau cerpen, dan diskusi-diskusi budaya yang diadakan secara rutin dan terjadwal. Cukup berbeda dengan galeri yang lain, KKF memberikan ruang alternatif yang memberikan kesempatan bagi seniman untuk memamerkan, mementaskan karya, dan mendiskusikan; sementara para penulis, wartawan, dan pengamat seni membuat ulasan, kritik atau apresiasinya. Diharapkan KKF mampu mempromosikan seniman muda dan menguji nilai-nilai dalam seni dan budaya kontemporer.

\section{B. Visi dan Misi Kedai Kebun Forum}

1. Visi

Bagi para seniman, Kedai Kebun Forum merupakan "ruang bermain", dalam arti, berani mencoba atau menisbikan nilai-nilai mapan yang kuat berakar dalam kesenian masa kini. Secara serius, sekaligus low profile Kedai Kebun Forum mencoba menjadi melting pot dari semua gagasan dan kreativitas yang lahir dan berkembang di wilayah seni, dengan meniadakan sekat atau batasan antara seni tinggi dan seni rendah, seni baik dan seni buruk. Kedai Kebun Forum percaya bahwa seni adalah bentuk refleksi sosial dan tidak otonom, sehingga seni apapun (dianggap baik ataupun buruk) dapat dilihat sebagai cerminan pergerakan sosial yang sedang terjadi.

\section{Misi}

- Menciptakan ruang pergaulan yang kritis terhadap fenomena sosial melalui aktivitas kesenian.

- Mendukung seniman yang cerdas, suka bermain, tidak peduli pada kategorisasi seni mutu \& tidak mutu untuk mempresentasikan karyanya.

- Memprovokasi kelompok-kelompok seni yang mempunyai komitmen yang sama dengan Kedai Kebun Forum untuk bersama-sama merekayasa terbentuknya cuaca seni yang segar, hidup, \& konstruktif.

- Memberikan alternatif tontonan kepada masyarakat.

- Memberikan inspirasi kepada komunitas seni yang ada untuk mencari pendapatan alternatif agar dapat menghidupi dirinya sendiri, dan kemudian mampu mendukung komunitas seni lainnya dan mendorong terbentuknya pola manajemen seni yang orisinal dan efisien. 


\section{Analisis Lingkungan}

1. Analisis Lingkungan Internal

a. Kekuatan (Strengths)

\begin{tabular}{cl}
\hline No. & Kekuatan \\
\hline 1. & Memiliki ruang fisik tetap dengan desain ruang yang nyaman. \\
2. & Memiliki nama (brand) yang diakui kualitas dan pengaruhnya. \\
3. & Memiliki jaringan usaha yang sudah mapan (dalam negeri dan luar negeri). \\
4. & Memiliki sistem kuratorial atau seleksi yang terstruktur. \\
\hline & b. Kelemahan (Weaknesses) \\
\hline No. & Kelemahan \\
\hline 1. & Seni rupa kontemporer masih asing bagi masyarakat. \\
2. & Ruang pamer yang tidak cukup luas. \\
4. & Menampilkan karya-karya yang tidak komersial. \\
\hline
\end{tabular}

2. Analisis Lingkungan Eksternal

a. Peluang (Opportunities)

\begin{tabular}{cl}
\hline No. & Peluang \\
\hline 1. & Semakin berkembangnya seni rupa kontemporer. \\
2. & Semakin banyak pengguna internet (memperluas jaringan melalui daring). \\
3. & Semakin meningkatnya apresiasi masyarakat terhadap kegiatan seni rupa \\
& kontemporer. \\
\hline & b. Ancaman (Threats) \\
\hline No. & Ancaman \\
\hline 1. & Masyarakat Jogja lebih mengetahui tentang keberadaan ruang seni lainnya. \\
2. & Galeri seni lainnya lebih gencar mengadakan kegiatan promo. \\
3. & Banyaknya galeri seni yang ada di Kota Yogyakarta. \\
\hline
\end{tabular}

\section{Tahapan dalam SWOT}

\section{Tahap Pemberian Bobot}

Menurut David \& David (2017) bobot menunjukkan tingkat kepentingan relatif suatu faktor terhadap keberhasilan usaha dalam suatu perusahaan atau organisasi. Bobot tiap faktor diperoleh dengan menentukan nilai tiap faktor terhadap total nilai faktor. Bobot yang diberikan berada pada kisaran 0,000 (tidak penting) hingga 1,000 (paling penting). Faktor-faktor yang memiliki pengaruh besar pada organisasi diberikan bobot yang tinggi. Jumlah seluruh bobot yang diberikan harus sama dengan 1,000. Bobot setiap variabel diperoleh dengan membagi total nilai setiap variabel terhadap total nilai keseluruhan variabel dengan rumus sebagai berikut: 
Skor di mana:

$$
\text { Bobot }=\frac{\text { Skor }}{\text { Total Skor }} \times 1
$$

- Skor adalah penilaian dari faktor strategis perusahaan.

- Bobot adalah jumlah skor dari faktor strategis perusahaan.

- Total skor adalah jumlah dari semua factor.

Jumlah semua bobot tidak boleh melebihi skor total 1,000. Penentuan bobot pada setiap variabel digunakan skala 1,2, 3. Penilaian untuk setiap skala dapat dijelaskan sebagai berikut:

$1=$ jika indikator horizontal kurang penting daripada indikator vertikal.

$2=$ jika indikator horizontal sama penting dengan indikator vertikal.

3 = jika indikator horizontal lebih penting daripada indikator vertikal.

Berikut ini rangkuman pemberian bobot Kedai Kebun Forum dari tiga orang key person, yakni Yustina Neni (Direktur KKF), Chairol Imam (seniman muda), dan Vitasari (pengunjung KKF).

Tabel 1. Pemberian Bobot Faktor Internal (Kekuatan dan Kelemahan)

\section{Kedai Kebun Forum}

\begin{tabular}{ccccc}
\hline $\begin{array}{c}\text { Faktor } \\
\text { Internal }\end{array}$ & Yustina Neni & Chairol Imam & Vitasari & Rata-rata \\
\hline A & 0.135 & 0.135 & 0.135 & 0.135 \\
B & 0.141 & 0.143 & 0.136 & $\mathbf{0 . 1 4 0}$ \\
C & 0.125 & 0.125 & 0.125 & 0.125 \\
D & 0.120 & 0.118 & 0.120 & 0.119 \\
E & 0.118 & 0.107 & 0.114 & $\mathbf{0 . 1 1 3}$ \\
F & 0.115 & 0.115 & 0.115 & 0.115 \\
G & 0.125 & 0.125 & 0.127 & 0.126 \\
H & 0.134 & 0.122 & 0.125 & 0.127 \\
\hline
\end{tabular}

Keterangan:

$\mathrm{A}=$ Memiliki ruang fisik tetap dengan desain ruang yang nyaman.

$\mathrm{B}=$ Memiliki nama (brand) yang diakui kualitas dan pengaruhnya.

$\mathrm{C}=$ Memiliki jaringan usaha yang sudah mapan (dalam negeri dan luar negeri).

$\mathrm{D}=$ Memiliki sistem kuratorial yang terstruktur.

$\mathrm{E}=$ Seni rupa kontemporer masih asing bagi masyarakat.

$\mathrm{F}=$ Ruang pamer yang tidak cukup luas.

$\mathrm{G}=$ Menampilkan karya-karya yang tidak komersial.

$\mathrm{H}=$ Kegiatan kesenian yang masih sedikit bila dibanding ruang seni lain.

Pada Tabel 1, menunjukkan bahwa Faktor Internal KKF (dilihat dari ratarata) memiliki bobot tertinggi adalah "Memiliki nama (brand) yang diakui kualitas dan pengaruhnya" dan bobot terendah adalah "Seni rupa kontemporer masih asing bagi masyarakat". 
Tabel 2. Pemberian Bobot Faktor Eksternal (Peluang dan Ancaman) Kedai Kebun Forum

\begin{tabular}{ccccc}
\hline $\begin{array}{c}\text { Faktor } \\
\text { Eksternal }\end{array}$ & Yustina Neni & Chairol Imam & Vitasari & Rata-rata \\
\hline A & 0.220 & 0.175 & 0.220 & $\mathbf{0 . 2 0 5}$ \\
\hline B & 0.150 & 0.140 & 0.220 & 0.170 \\
C & 0.145 & 0.140 & 0.150 & $\mathbf{0 . 1 4 5}$ \\
\hline D & 0.200 & 0.150 & 0.155 & 0.168 \\
E & 0.150 & 0.150 & 0.155 & 0.153 \\
F & 0.150 & 0.180 & 0.150 & 0.160 \\
\hline & & & Total Rata-rata & $\mathbf{1 . 0 0 0}$ \\
\hline
\end{tabular}

Keterangan:

A = Semakin berkembangnya seni rupa kontemporer.

$\mathrm{B}=$ Semakin banyak pengguna internet (memperluas jaringan melalui daring).

$\mathrm{C}=$ Semakin meningkatnya apresiasi masyarakat terhadap kegiatan seni rupa kontemporer.

$\mathrm{D}=$ Masyarakat Jogja lebih mengetahui tentang keberadaan ruang seni lainnya.

$\mathrm{E}=$ Galeri seni lainnya lebih gencar mengadakan kegiatan promo.

$\mathrm{F}=$ Banyaknya galeri seni yang ada di Kota Yogyakarta.

Pada Tabel 2, menunjukkan bahwa Faktor Eksternal KKF (dilihat dari ratarata) yang memiliki bobot tertinggi adalah "Semakin berkembangnya seni rupa kontemporer" dan bobot yang terendah adalah "Semakin meningkatnya apresiasi masyarakat terhadap kegiatan seni rupa kontemporer".

\section{Tahap Pemberian Peringkat}

Peringkat menggambarkan seberapa efektif strategi organisasi atau perusahaan saat ini dalam merespons faktor strategi yang ada. Penilaian peringkat untuk lingkungan diberikan dalam skala dengan pembagian sebagai berikut:

\begin{tabular}{|c|c|}
\hline \multicolumn{2}{|c|}{ Lingkungan Eksternal } \\
\hline $\begin{array}{l}\text { Aspek Peluang: } \\
\text { rating } 4=\text { respons sangat superior } \\
\text { rating } 3=\text { respons di atas rata-rata } \\
\text { rating } 2=\text { respons rata-rata } \\
\text { rating } 1=\text { respons di bawah rata-rata }\end{array}$ & $\begin{array}{l}\text { Aspek Ancaman } \\
\text { rating } 4=\text { respons di bawah rata-rata } \\
\text { rating } 3=\text { respons rata-rata } \\
\text { rating } 2=\text { respons di atas rata-rata } \\
\text { rating } 1=\text { respons sangat superior }\end{array}$ \\
\hline \multicolumn{2}{|c|}{ Lingkungan Internal } \\
\hline $\begin{array}{l}\text { Aspek Peluang: } \\
\text { rating } 4=\text { sangat kuat } \\
\text { rating } 3=\text { kuat } \\
\text { rating } 2=\text { lemah } \\
\text { rating } 1=\text { sangat lemah }\end{array}$ & $\begin{array}{l}\text { Aspek Ancaman } \\
\text { rating } 4=\text { sangat lemah } \\
\text { rating } 3=\text { lemah } \\
\text { rating } 2=\text { kuat } \\
\text { rating } 1=\text { sangat kuat }\end{array}$ \\
\hline
\end{tabular}


Berikut ini rangkuman pemberian bobot Kedai Kebun Forum dari tiga orang key person, yakni Yustina Neni (Direktur KKF), Chairol Imam (seniman muda), dan Vitasari (pengunjung KKF).

a. Kekuatan (Strengths)

Tabel 3. Pemberian Peringkat Faktor Kekuatan Kedai Kebun Forum

\begin{tabular}{clcccc}
\hline No. & \multicolumn{1}{c}{ Kekuatan } & $\begin{array}{c}\text { Yustina } \\
\text { Neni }\end{array}$ & $\begin{array}{c}\text { Chairol } \\
\text { Imam }\end{array}$ & Vitasari & Rata-rata \\
\hline A & $\begin{array}{l}\text { Memiliki ruang fisik tetap dengan } \\
\text { desain ruang yang nyaman. }\end{array}$ & 4 & 3 & 3 & 3.333 \\
B & $\begin{array}{l}\text { Memiliki nama (brand) yang } \\
\text { diakui kualitas dan pengaruhnya. }\end{array}$ & 4 & 3 & 2 & 3.000 \\
C & $\begin{array}{l}\text { Memiliki jaringan usaha yang } \\
\text { sudah mapan (dalam negeri dan } \\
\text { luar negeri). }\end{array}$ & 2 & 2 & 3 & $\mathbf{2 . 3 3 3}$ \\
D & $\begin{array}{l}\text { Memiliki sistem kuratorial yang } \\
\text { terstruktur. }\end{array}$ & 3 & 2 & 3 & 2.667 \\
\hline
\end{tabular}

Berdasarkan Tabel 3, peringkat terhadap kekuatan KKF yang tertinggi adalah "Memiliki ruang fisik tetap dengan desain ruang yang nyaman" sedangkan peringkat yang terendah adalah "Memiliki jaringan usaha yang sudah mapan (dalam negeri dan luar negeri)".

b. Kelemahan (Weaknesses)

Tabel 4. Pemberian Peringkat Faktor Kelemahan Kedai Kebun Forum

\begin{tabular}{clcccc}
\hline No. & \multicolumn{1}{c}{ Kelemahan } & $\begin{array}{c}\text { Yustina } \\
\text { Neni }\end{array}$ & $\begin{array}{c}\text { Chairol } \\
\text { Imam }\end{array}$ & Vitasari & Rata-rata \\
\hline E & $\begin{array}{l}\text { Seni rupa kontemporer masih asing } \\
\text { bagi masyarakat. }\end{array}$ & 1 & 1 & 3 & $\mathbf{1 . 6 6 7}$ \\
F & $\begin{array}{l}\text { Ruang pamer yang tidak cukup } \\
\text { luas. }\end{array}$ & 3 & 2 & 3 & 2.667 \\
G & $\begin{array}{l}\text { Menampilkan karya-karya yang } \\
\text { tidak komersial. }\end{array}$ & 2 & 2 & 3 & 2.333 \\
H & $\begin{array}{l}\text { Kegiatan kesenian yang masih } \\
\text { sedikit bila dibanding ruang seni } \\
\text { lain. }\end{array}$ & 3 & 3 & 3 & $\mathbf{3 . 0 0 0}$ \\
\hline
\end{tabular}

Berdasarkan Tabel 4, peringkat terhadap kekuatan KKF yang tertinggi adalah "Kegiatan kesenian yang masih sedikit bila dibanding ruang seni lain" sedangkan peringkat yang terendah adalah "Seni rupa kontemporer masih asing bagi masyarakat". 
c. Peluang (Opportunities)

Tabel 5. Pemberian Peringkat Faktor Peluang Kedai Kebun Forum

\begin{tabular}{clcccc}
\hline No. & \multicolumn{1}{c}{ Peluang } & $\begin{array}{c}\text { Yustina } \\
\text { Neni }\end{array}$ & $\begin{array}{c}\text { Chairol } \\
\text { Imam }\end{array}$ & Vitasari & Rata-rata \\
\hline A & $\begin{array}{l}\text { Semakin berkembangnya seni rupa } \\
\text { kontemporer. }\end{array}$ & 3 & 2 & 3 & $\mathbf{2 . 6 6 7}$ \\
B $\quad \begin{array}{l}\text { Semakin banyak pengguna internet } \\
\text { (memperluas jaringan melalui } \\
\text { daring). }\end{array}$ & 3 & 3 & 3 & 3.000 \\
C $\quad \begin{array}{l}\text { Semakin meningkatnya apresiasi } \\
\text { masyarakat terhadap kegiatan seni } \\
\text { rupa kontemporer. }\end{array}$ & 3 & 4 & 4 & $\mathbf{3 . 6 6 7}$ \\
\hline
\end{tabular}

Berdasarkan Tabel 5, peringkat terhadap kekuatan KKF yang tertinggi adalah "Semakin meningkatnya apresiasi masyarakat terhadap kegiatan seni rupa kontemporer" sedangkan peringkat yang terendah adalah "Semakin berkembangnya seni rupa kontemporer".

\section{d. Ancaman (Threats)}

Tabel 6. Pemberian Peringkat Faktor Ancaman Kedai Kebun Forum

\begin{tabular}{clcccc}
\hline No. & \multicolumn{1}{c}{ Ancaman } & $\begin{array}{c}\text { Yustina } \\
\text { Neni }\end{array}$ & $\begin{array}{c}\text { Chairol } \\
\text { Imam }\end{array}$ & Vitasari & Rata-rata \\
\hline D & $\begin{array}{l}\text { Masyarakat Jogja lebih } \\
\text { mengetahui tentang keberadaan } \\
\text { ruang seni lainnya. }\end{array}$ & 2 & 1 & 3 & $\mathbf{2 . 0 0 0}$ \\
E $\quad \begin{array}{l}\text { Galeri seni lainnya lebih gencar } \\
\text { mengadakan kegiatan promo. }\end{array}$ & 2 & 3 & 3 & 2.667 \\
F & $\begin{array}{l}\text { Banyaknya galeri seni yang ada di } \\
\text { Kota Yogyakarta. }\end{array}$ & 3 & 3 & 4 & $\mathbf{3 . 3 3 3}$ \\
\hline
\end{tabular}

Berdasarkan Tabel 6, peringkat terhadap kekuatan KKF yang tertinggi adalah "Banyaknya galeri seni yang ada di Kota Yogyakarta" sedangkan peringkat yang terendah adalah "Masyarakat Jogja lebih mengetahui tentang keberadaan ruang seni lainnya”.

e. Hasil Matriks Internal Factor Evaluation (IFE)

Tabel 7. Hasil Analisis Matriks IFE Kedai Kebun Forum

\begin{tabular}{ccccc}
\hline No. & \multicolumn{1}{c}{ Faktor Internal } & Bobot & Peringkat & Nilai \\
\hline $\begin{array}{c}\text { Kekuatan } \\
\text { A } \quad \begin{array}{l}\text { Memiliki ruang fisik tetap dengan desain ruang } \\
\text { yang nyaman. }\end{array}\end{array}$ & 0.135 & 3.333 & 0.450 \\
B $\quad \begin{array}{l}\text { Memiliki nama (brand) yang diakui kualitas dan } \\
\text { pengaruhnya. }\end{array}$ & 0.140 & 3.000 & 0.420 \\
C $\quad \begin{array}{l}\text { Memiliki jaringan usaha yang sudah mapan } \\
\text { (dalam negeri dan luar negeri). }\end{array}$ & 0.125 & 2.333 & 0.292 \\
D $\quad$ Memiliki sistem kuratorial yang terstruktur. & 0.119 & 2.667 & 0.317 \\
\hline & \multicolumn{3}{c}{ Total Nilai Kekuatan } & 1.479 \\
\hline
\end{tabular}




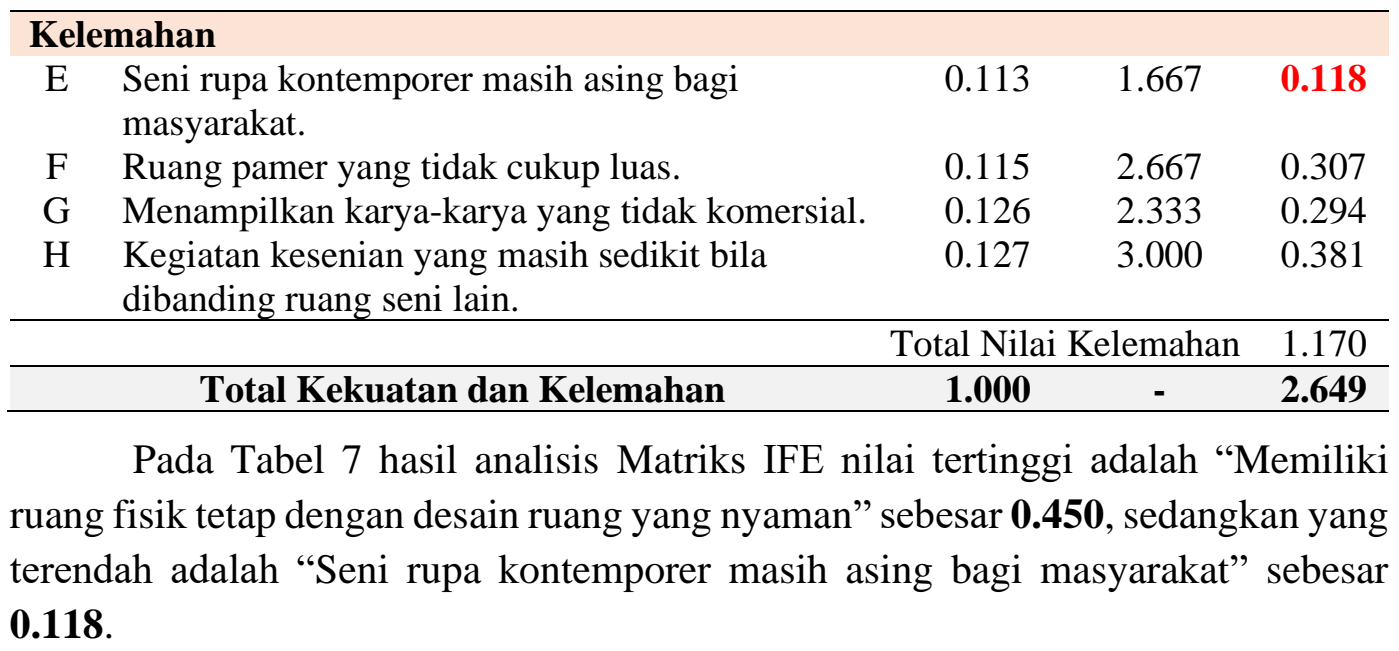

f. Hasil Matriks External Factor Evaluation (EFE)

Tabel 8. Hasil Analisis Matriks EFE Kedai Kebun Forum

\begin{tabular}{|c|c|c|c|c|}
\hline No. & Faktor Eksternal & Bobot & Peringkat & Nilai \\
\hline \multicolumn{5}{|c|}{ Peluang } \\
\hline A & Semakin berkembangnya seni rupa kontemporer. & 0.205 & 2.667 & 0.547 \\
\hline B & $\begin{array}{l}\text { Semakin banyak pengguna internet (memperluas } \\
\text { jaringan melalui daring). }\end{array}$ & 0.170 & 3.000 & 0.510 \\
\hline \multirow[t]{2}{*}{$\mathrm{C}$} & $\begin{array}{l}\text { Semakin meningkatnya apresiasi masyarakat } \\
\text { terhadap kegiatan seni rupa kontemporer. }\end{array}$ & 0.145 & 3.667 & 0.532 \\
\hline & & \multicolumn{2}{|c|}{ Total Nilai Peluang } & 1.588 \\
\hline \multicolumn{5}{|c|}{ Ancaman } \\
\hline $\mathrm{D}$ & $\begin{array}{l}\text { Masyarakat Jogja lebih mengetahui tentang } \\
\text { keberadaan ruang seni lainnya. }\end{array}$ & 0.168 & 2.000 & 0.336 \\
\hline $\mathrm{E}$ & $\begin{array}{l}\text { Galeri seni lainnya lebih gencar mengadakan } \\
\text { kegiatan promo. }\end{array}$ & 0.153 & 2.667 & 0.408 \\
\hline $\mathrm{F}$ & $\begin{array}{l}\text { Banyaknya galeri seni yang ada di Kota } \\
\text { Yogyakarta. }\end{array}$ & 0.160 & 3.333 & 0.533 \\
\hline & & \multicolumn{2}{|c|}{ Total Nilai Ancaman } & 1.277 \\
\hline & Total Peluang dan Ancaman & 1.000 & - & 2.866 \\
\hline
\end{tabular}

Pada Tabel 8 hasil analisis Matriks EFE nilai tertinggi adalah "Semakin berkembangnya seni rupa kontemporer" sebesar $\mathbf{0 . 5 4 7}$, sedangkan yang terendah adalah "Masyarakat Jogja lebih mengetahui tentang keberadaan ruang seni lainnya" sebesar 0.336.

\section{Tahap Pencocokan}

a. Hasil Matriks IE (Internal-Eksternal)

Tahap ini merupakan tahap pencocokan dengan memasukkan hasil pembobotan dan peringkat pada Matriks EFE dan IFE ke dalam Matriks IE. Total nilai tertimbang pada Matriks EFE dan IFE akan berada pada kisaran 1,0 (terendah) 
hingga 4,0 (tertinggi) dengan nilai rata-rata 2,5. Matriks IE mempunyai sembilan sel strategi yang dapat dikelompokkan menjadi tiga sel strategi utama, yaitu:

1) Growth and Build (Tumbuh dan Bina) berada dalam sel I, II, dan IV. Strategi yang cocok adalah intensif (penetrasi pasar, pengembangan pasar, dan pengembangan produk) atau integrasi (integrasi ke belakang, integrasi ke depan, dan integrasi horizontal).

2) Hold and Maintain (Pertahankan dan Pelihara) dilakukan untuk sel III, V, dan VII. Strategi umum yang dipakai adalah penetrasi pasar dan pengembangan produk.

3) Harvest or Divest (Panen atau Divestasi) dipakai untuk sel VI, VIII, dan IX. Strategi umum yang dipakai adalah strategi divestasi, strategi diversifikasi konglomerat, dan strategi likuidasi.

Berdasarkan hasil IFE sebesar 2.649 dan EFE sebesar 2.866 maka, posisi KKF melalui Matriks IE yaitu:

\section{Tabel 9. Matriks IE Kedai Kebun Forum}

\begin{tabular}{|c|c|c|c|}
\hline \multicolumn{4}{|c|}{ Total Skor IFE } \\
\hline 4,0 & 3,0 & 2,0 & 1,0 \\
\hline 3,0 & I & II & III \\
\hline 2,0 & IV & $\mathrm{V}$ & VI \\
\hline 1,0 & VII & VIII & IX \\
\hline
\end{tabular}

Posisi KKF melalui Matriks IE menunjukkan Hold and Maintain (Pertahankan dan Pelihara) karena berada pada posisi V. Strategi umum yang dipakai adalah penetrasi pasar dan pengembangan produk.

b. Kuadran Analisis SWOT

Untuk kuadran analisis SWOT Kedai Kebun Forum dihitung berdasarkan berikut:

$$
\begin{aligned}
\text { Nilai Faktor Internal } & =\text { Kekuatan }- \text { Kelemahan } \\
& =1.479-1.170 \\
& =\mathbf{0 . 3 0 9} \\
\text { Nilai Faktor Eksternal } & =\text { Peluang }- \text { Ancaman } \\
& =1.588-1.277 \\
& =\mathbf{0 . 3 1 1}
\end{aligned}
$$




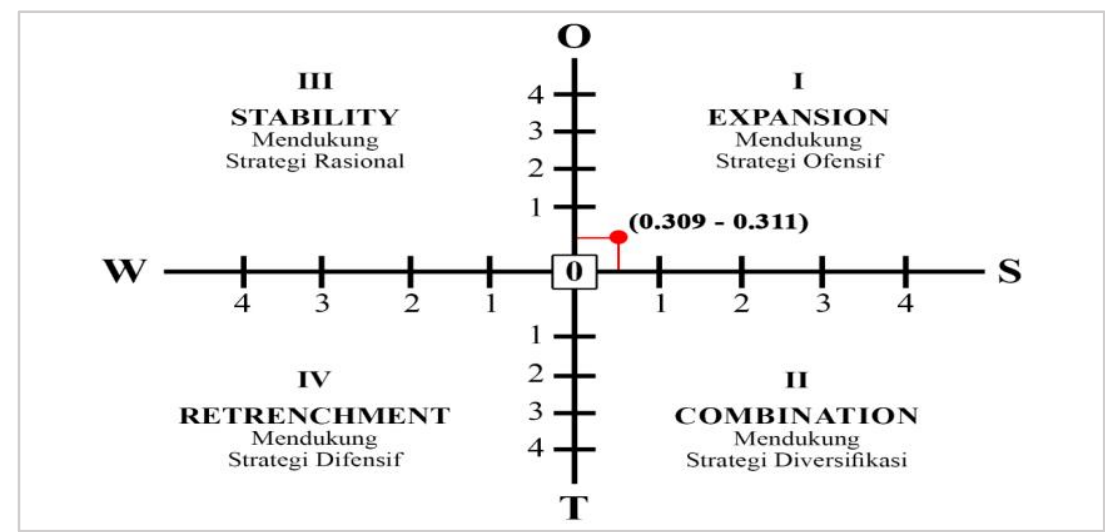

Gambar 1. Kuadran Analisis SWOT Kedai Kebun Forum

\section{c. Matriks SWOT}

Matriks SWOT diperoleh dengan memasangkan faktor-faktor eksternal dengan faktor-faktor internal. Dalam Matriks SWOT diperlihatkan kesesuaian antara Kekuatan, Kelemahan, Peluang, dan Ancaman seperti terlihat pada tabel berikut.

\section{Tabel 10. Alternatif Strategi dalam Matriks SWOT}

\begin{tabular}{|c|c|c|}
\hline Eksternal Internal & $\begin{array}{c}\text { Strength (S) } \\
\text { Faktor Kekuatan }\end{array}$ & $\begin{array}{c}\text { Weakness }(\mathbf{W}) \\
\text { Faktor Kelemahan }\end{array}$ \\
\hline $\begin{array}{c}\text { Opportunities }(\mathbf{O}) \\
\text { Faktor Peluang }\end{array}$ & $\begin{array}{c}\text { Strategi SO } \\
\text { Ciptakan Strategi yang } \\
\text { menggunakan kekuatan } \\
\text { untuk memanfaatkan } \\
\text { peluang. }\end{array}$ & $\begin{array}{c}\text { Strategi WO } \\
\text { Ciptakan strategi yang } \\
\text { meminimalkan kelemahan } \\
\text { untuk memanfaatkan peluang. }\end{array}$ \\
\hline $\begin{array}{c}\text { Threats }(\mathbf{T}) \\
\text { Faktor Ancaman }\end{array}$ & $\begin{array}{c}\text { Strategi ST } \\
\text { Ciptakan strategi yang } \\
\text { menggunakan kekuatan } \\
\text { untuk mengatasi ancaman. }\end{array}$ & $\begin{array}{c}\text { Strategi WT } \\
\text { Ciptakan strategi yang } \\
\text { meminimalkan kelemahan } \\
\text { dan menghindari ancaman. }\end{array}$ \\
\hline
\end{tabular}

4. Tahap Keputusan

Hasil Matriks SWOT memberikan beberapa alternatif strategi, yaitu:

SO : 1. Membuka kerja kreatif dengan pendekatan berbeda dari para seniman terkait fenomena sosial yang terjadi saat ini.

2. Menjadi tempat penghubung antara seniman dan publik. 
WO : 1. Menjaring massa melalui berbagai bentuk kesenian yang khas dan cair dari lingkup rupa, sastra, musik, hingga perfilman.

2. Menciptakan iklim kreatif yang terbuka lewat pameran karya seni, musik eksperimental, movie screening, dan diskusi berbagai macam keilmuan.

ST : 1. Memberikan tempat bagi mahasiswa, seniman-seniman muda, dan para pekerja kreatif lainnya untuk bereksperimen dan menyampaikan karyanya ke publik secara lebih mudah.

2. Memberi pengaruh terhadap praktik seni yang dikelola oleh seniman serta sistem presentasi yang berdampak pada nilai ekonomi.

WT : 1. Membangun wacana-wacana baru yang memungkinkan untuk menyebarkan pengetahuan dan pemahaman mengenai karya seni kontemporer.

2. Menggelar agenda seni yang menampung serta merepresentasikan setiap gagasan.

a. Tahap Keputusan berdasarkan Matriks IE

Posisi Kedai Kebun Forum Matriks IE menunjukkan Hold and Maintain

(Pertahankan dan Pelihara) karena berada pada posisi V. Strategi umum yang dipakai adalah penetrasi pasar dan pengembangan produk.

1) Penetrasi Pasar, menguatkan program dengan karya yang terseleksi disertai wacana (makna) yang memadai dan merancang program (pameran, pertunjukan seni, lokakarya, diskusi) dengan visi seni rupa yang tajam.

2) Pengembangan Produk/Karya, membangun citra dengan memperkenalkan karya-karya perupa yang sulit diserap oleh galeri-galeri seni yang kebanyakan menitikberatkan aspek komersial maupun bentuk seni yang telah mapan, diberi kesempatan untuk dimediasikan kepada khalayak yang lebih luas.

b. Tahap Keputusan berdasarkan kuadran analisis SWOT

Kuadran analisis SWOT KKF menunjukkan posisinya berada pada kuadran I Expansion sehingga diperlukan pemilihan strategi yang berupa penggunaan setiap kekuatan untuk menghadapi setiap ancaman. Posisi tersebut mengarah pada strategi ST yaitu:

1) Memberikan tempat bagi mahasiswa, seniman-seniman muda, dan para pekerja kreatif lainnya untuk bereksperimen dan menyampaikan karyanya ke publik secara lebih mudah.

2) Memberi pengaruh terhadap praktik seni yang dikelola oleh seniman serta sistem presentasi yang berdampak pada nilai ekonomi. 


\section{KESIMPULAN}

Tujuan utama pada penyusunan jurnal ini adalah untuk mengembangkan strategi Kedai Kebun Forum. Berdasarkan analisis Matriks IE (Internal-Eksternal) dan kuadran SWOT maka, dapat disimpulkan strategi Kedai Kebun Forum sebagai berikut.

Strategi Generik: Ekspansi (Expansion)

Variasi Strategi: 1. Penetrasi Pasar, yakni menguatkan program dengan karya yang terseleksi disertai wacana (makna) yang memadai dan merancang program (pameran, pertunjukan seni, lokakarya, diskusi) dengan visi seni rupa yang tajam.

2. Pengembangan Produk/Karya, yakni membangun citra dengan memperkenalkan karya-karya perupa yang sulit diserap oleh galeri-galeri seni yang kebanyakan menitikberatkan aspek komersial maupun bentuk seni yang telah mapan, diberi kesempatan untuk dimediasikan kepada khalayak yang lebih luas.

\section{SARAN}

\section{A. Saran untuk Pengelola}

Kedai Kebun Forum mempunyai bidang garapan yang kurang populer. Promosi yang dilakukan melalui media cetak maupun digital (sosial media, website, dll) mampu menarik perhatian publik untuk datang melihat atau mengikuti kegiatan yang dilakukan oleh KKF. Berdasarkan hasil matriks IE dan kuadran SWOT, telah memunculkan rekomendasi strategi-strategi yang bisa digunakan untuk mendukung pencapaian visi dan misi KKF. Namun dalam penerapan strategi ini hendaknya disesuaikan pula dengan perkembangan seni rupa.

\section{B. Saran untuk penelitian lebih lanjut}

Penelitian ini terbatas hanya pada perumusan strategi, belum sampai pada tahap implementasi dan evaluasi strategi. Oleh sebab itu, peneliti menyarankan untuk penelitian selanjutnya agar lebih mengkaji pada tahapan implementasi strategi dan evaluasi strategi yang digunakan dalam manajemen strategi pengelolaan ruang seni khususnya di Kedai Kebun Forum, sehingga dapat memberikan kontribusi dalam meningkatkan pengelolaan KKF. Serta dapat memberikan kontribusi positif bagi penelitian mengenai ruang seni yang terdapat di Indonesia. 


\section{KEPUSTAKAAN}

David, Fred R. \& David, Forest R. (2017). Strategic Management: A Competitive Advantage Approach, Concepts, and Cases, Sixteenth Edition. England: Pearson Education.

Dani, Iwan Setiadi. (2019). "Perkembangan Studi Tata Kelola Seni dan Risetnya di Aras Global dan Lokal". Jurnal Tata Kelola Seni, Volume 5 No.2 Desember 2019: $87-102$.

Fulkova, Marie. (2011). "The Orbis Pictus we all live in coding the World with differently-abled visitors in the Gallery of Contemporary Art". Procedia Social and Behavioral Sciences, Volume 30 No.491 Oktober 2011: 2525 2534.

Rangkuti, Freddy. (2018). Analisis SWOT: Teknik Membedah Kasus Bisnis Cara Perhitungan Bobot, Rating, dan OCAI, Cetakan Keduapuluh Empat. Jakarta: PT Gramedia Pustaka Utama.

Indarto, Kuss \& Santoso, B.S. (2015). Melacak Jejak Rupa. Yogyakarta: UPTD Taman Siswa.

\section{Informan}

Yustina Neni Nugraheni (52 Tahun). Direktur Kedai Kebun Forum (KKF), Yogyakarta.

Chairol Imam (25 Tahun). Seniman Muda (Praktisi).

Vitasari (26 Tahun). Pengunjung Kedai Kebun Forum (KKF). 